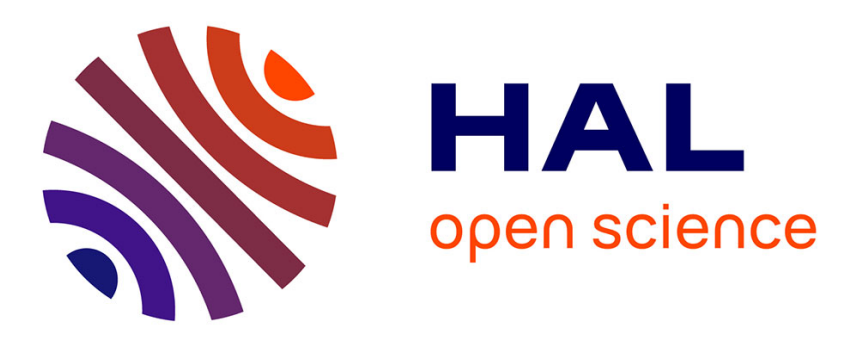

\title{
Disconnection arrays in a rhombohedral twin in $\alpha$-alumina
}

Sylvie Lartigue-Korinek, Serge Hagege, Christian Kisielowski, Anna Serra

\section{To cite this version:}

Sylvie Lartigue-Korinek, Serge Hagege, Christian Kisielowski, Anna Serra. Disconnection arrays in a rhombohedral twin in $\alpha$-alumina. Philosophical Magazine, 2008, 88 (10), pp.1569-1579. 10.1080/14786430802235804. hal-00513912

\section{HAL Id: hal-00513912 \\ https://hal.science/hal-00513912}

Submitted on 1 Sep 2010

HAL is a multi-disciplinary open access archive for the deposit and dissemination of scientific research documents, whether they are published or not. The documents may come from teaching and research institutions in France or abroad, or from public or private research centers.
L'archive ouverte pluridisciplinaire HAL, est destinée au dépôt et à la diffusion de documents scientifiques de niveau recherche, publiés ou non, émanant des établissements d'enseignement et de recherche français ou étrangers, des laboratoires publics ou privés. 


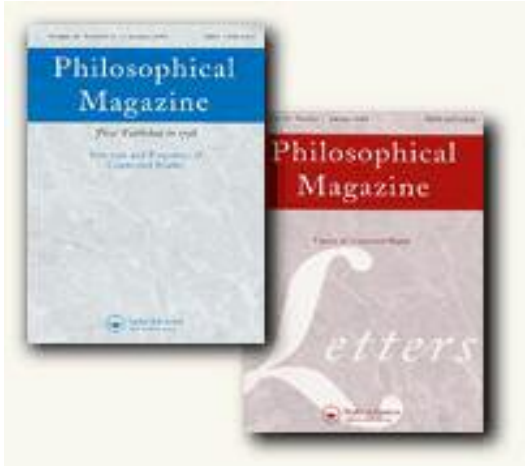

Disconnection arrays in a rhombohedral twin in $\alpha$-alumina

\begin{tabular}{|r|l|}
\hline Journal: & Philosophical Magazine \& Philosophical Magazine Letters \\
\hline Manuscript ID: & TPHM-08-Mar-0078.R1 \\
\hline Journal Selection: & Philosophical Magazine \\
\hline Date Submitted by the & 27-May-2008 \\
\hline Complete List of Authors: & $\begin{array}{l}\text { Lartigue-Korinek, Sylvie; Institut de Chimie et des Matériaux Paris } \\
\text { Est, UMR 7182 Université Paris 12 et CNRS } \\
\text { Hagege, Serge; Institut de Chimie et des Matériaux Paris Est, UMR } \\
\text { 7182 Université Paris 12 et CNRS } \\
\text { Kisielowski, Christian; National Center for Electron Microscopy, MS } \\
\text { 72-150, Lawrence Berkeley National Laboratory, Berkeley } \\
\text { Serra, Anna; Depart. Matemàtica Aplicada III, Universitat } \\
\text { Politècnica de Catalunya }\end{array}$ \\
\hline Keywords: & $\begin{array}{l}\text { alumina, dislocations, grain boundary structure, transmission } \\
\text { electron microscopy }\end{array}$ \\
\hline Keywords (user supplied): & \begin{tabular}{l} 
alumina, dislocations, grain boundary structure \\
\hline
\end{tabular} \\
\hline
\end{tabular}

\section{s) ScholarONE" \\ Manuscript Central}




\title{
Disconnection arrays in a rhombohedral twin in $\alpha$-alumina
}

\author{
Sylvie Lartigue-Korinek \\ Corresponding author \\ Institut de Chimie et des Matériaux Paris Est, UMR 7182 Université Paris 12 et CNRS, 2-8 \\ rue H. Dunant, 94320 Thiais - FRANCE \\ email : sylvie.lartigue@icmpe.cnrs.fr
}

Serge Hagege

Institut de Chimie et des Matériaux Paris Est, UMR 7182 Université Paris 12 et CNRS, 2-8 rue H. Dunant, 94320 Thiais - FRANCE

email : serge.hagege@,icmpe.cnrs.fr

\author{
Christian Kisielowski \\ National Center for Electron Microscopy, MS 72-150, Lawrence Berkeley National \\ Laboratory, Berkeley, CA 94720-8250, USA \\ email : $\underline{\text { CFKisielowski@,lbl.gov }}$
}

\begin{abstract}
Anna Serra
Depart. Matemàtica Aplicada III, Universitat Politècnica de Catalunya, Barcelona, SPAIN email : a.serra@upc.edu
\end{abstract}

Length of the manuscript : 3815 words 


\begin{abstract}
Interfacial defects such as grain boundary dislocations are known to play an important role in the creep behavior of alumina. In the present work interfacial defects are analyzed in detail using a Volterra approach without a reference to a near-coincidence description. We investigate disconnections (boundary steps with dislocation character) in a diffusion-bonded alumina bicrystal with a misorientation close to the rhombohedral twin by conventional and atomic resolution electron microscopy.

The bicrystal contains two arrays of parallel disconnections with Burgers vectors that have alternating equal and opposite twist components, so there is no long-range stress field. This configuration is discussed in terms of the stability of different grain boundary disconnection arrangements. The complex core structure of the defects is revealed by high resolution electron microscopy using exit wave reconstruction. It is shown that the defects are dissociated into two partials that delimit grain boundary segments with alternating structure.
\end{abstract}

Key words : grain boundary structure, dislocations, alumina, transmission electron microscopy

\title{
1- Introduction
}

Grain boundary (GB) dislocations play a major role in high temperature deformation of alumina [1]. In fine-grained alumina, the main deformation process is grain boundary sliding, which involves GB dislocation glide and climb, processes that are controlled by GB diffusion $[1,2]$. Indeed, it has been found that the number of dislocation arrays in GBs increases after deformation. In the presence of a segregating element that strongly decreases GB diffusion, most GBs display arrays of dislocations. This is the case for yttrium, which is known to reduce the rate of creep $[3,4]$. Yttrium is strongly segregated to GBs [5] where it decreases intergranular diffusion [6]. It was assumed that it inhibits dislocation motion by climb. A thorough analysis of the GB structure and chemistry in undoped and yttrium-doped bicrystals close to the rhombohedral twin orientation was then undertaken. First investigations by conventional and analytical microscopy on the doped bicrystal reveal that yttrium segregates to GB dislocations [7]. 
An accurate knowledge of the structure of GB defects at the atomic level in the undoped bicrystal is a prerequisite to further analyses of the doped bicrystal. This is the aim of the present work.

The interfacial defects in the rhombohedral twin are discontinuities of the perfect twin structure that have both dislocation and step-like character. Such defects are known as disconnections [10]. Their dislocation character is characterized by their Burgers vector, which is related to the crystal symmetries that are broken when the bicrystal is created. In rhombohedral crystals with non-rational values of c/a, pure steps with no dislocation character are not possible due to the absence of periodicity perpendicular to the interface.

In previous work, the characteristics of interfacial dislocations were analyzed on the basis of near coincidence descriptions for the rhombohedral symmetry $[8,9]$. In the present paper we report an exact characterization of line defects linked to rhombohedral twins using the topological theory of interfacial defects based on geometrical considerations [10]. The disconnections analyzed present a wide core whose structure is visualized by atomic resolution imaging using the technique of exit wave reconstruction from a focal series of high resolution images.

\section{2- Experimental}

The alumina bicrystal was prepared by diffusion bonding at $1700^{\circ} \mathrm{C}$ for 30 minutes [11]. The sample was first thinned by the mechanical tripod technique, then made electron transparent by a soft argon ion milling (DUO-MILL Gatan at $3 \mathrm{kV}$ with a $0.5 \mathrm{~mA} \mathrm{Ar}{ }^{+}$beam current). A conductive amorphous carbon layer was deposited by evaporation on both foil faces. The sample was finally annealed under high vacuum $\left(10^{-6}\right.$ Torr $)$ in order to prevent further contamination under the electron beam in the microscope.

Conventional 2-beam diffraction contrast analysis was performed on a JEOL 2000EX. Classical HRTEM images were recorded along the $[2 \overline{1} \overline{1} 0]$ zone axis for one crystal with a Topcon ABT002 operated at $200 \mathrm{kV}$ that exhibits a Scherzer point resolution of $1.8 \AA$. SubÅngström phase and amplitude images of the complex electron exit wave function were reconstructed from a focal series of 20 lattice images recorded on a CM300 FEG/UT instrument with a $0.8 \AA$ information limit [12]. The image simulations were performed by multislice calculations with the MacTempas and CrystalKit software packages [13].

\section{3- Results and discussion}


The grain boundary contains two periodic arrays of disconnections $\mathrm{X}$ and $\mathrm{Y}$, alternately distributed and spaced by $26 \mathrm{~nm}$, which account for the tilt deviation from the perfect twin orientation (figure 1). Their Burgers vectors are $\vec{b}_{x}$ and $\vec{b}_{y}$ respectively. The deviation axis and angle $(\rho, \Delta \theta)$ are determined by setting common axes of the twin parallel to the electron beam. In the experiment, the axes are not strictly parallel and $(\rho, \Delta \theta)$ are deduced from the measured displacement vectors joining the Kikuchi map centers for each nearly common axis. The deviation is mainly tilt in character with $\Delta \theta=0.8^{\circ}$. The low magnification high resolution image in figure 2 reveals that different step heights are associated with each type of dislocation

\section{3-1- Twin structure}

The rhombohedral twin is described by a common dense (01 $\overline{1} 2)$ plane, and a common $[01 \overline{1} \overline{1}]$ direction. The twin structure, far from the defects, is based on the centers of symmetry of the structure (i.e. non-occupied sites of the aluminum sublattice (figure 3)). The white dots in the lattice image correspond to empty octahedral sites of the aluminum sublattice, as can be seen from the inserted geometrical model. From symmetry considerations on the various dichromatic complexes, four different structural models characterized by different translation states have been proposed [9]. They provide simulated images, which describe the experimental HRTEM micrograph reasonably well. However, only one structure leads to the least distorted Al-O bonds at the interface and it contains a 2-fold screw symmetry axis including a glide component. This structure was also derived from mechanical twinning experiments and called "screw twins" [14]. The glide component is apparent in figure 4 , which was recorded with a $[20 \overline{2} \overline{1}]$ axis parallel to the electron beam.

Recent experiments [15] give similar results and simulations using local density functional theory (LDFT) [16] and lattice static calculations [17] confirm the lowest energy of this "screw twin" configuration.

\section{3-2- Interfacial defects}

The interfacial defects should compensate the slight misorientation from the perfect twin structure. These defects are characterized using a Volterra approach. Their Burgers vector is 
given by $\vec{b}=t(\lambda)-\operatorname{Pt}(\mu)$ where $t(\lambda)$ and $t(\mu)$ are translation vectors in the upper $(\lambda)$ and the lower crystal $(\mu)$ respectively [7]. The transformation matrix P relates the $\mu$ coordinate system to the $\lambda$ system and was obtained using the method described in [18]. A detailed description of this approach, including the rotation matrix, is given in the appendix.

Figure 5 depicts HRTEM image of X and Y disconnections. An example of the circuit around the defect in each crystal is shown in (a). The additional $(01 \overline{1} 2)$ and $(01 \overline{1} \overline{4})$ planes are indicated. The GB plane is lower on the right side of the defect.

$\mathrm{AB}(\lambda)$ and $\mathrm{AB}(\mu)$ are translation vectors that join two equivalent lattice sites common to crystals $\lambda$ and $\mu$. The circuits are reproduced in the dichromatic pattern as indicated in figure 6. The defect Y pictured in fig. 5(a) has a $\vec{b}_{-3 /-4}$ Burgers vector (descending step, $3 d(01 \overline{1} 2)$ in crystal $\lambda, 4 d(01 \overline{1} 2)$ in crystal $\mu$, see appendix $))$. It includes a screw component $\pm 1 / 6\left[\begin{array}{lll}2 & \overline{1} & 1\end{array}\right]$ out of the projection plane. A similar procedure gives a $\vec{b}_{-4 /-5}$ Burgers vector for the dislocation $\mathrm{X}$ (pictured in fig. 5(b)), which also includes a screw component. The translation vectors $\vec{t}(\lambda)$ and $\vec{t}(\mu)$ used to identify the Burgers vector are defined in figure 7 . Uncertainties about the sign of the screw components are removed by a conventional contrast analysis of disconnections observed in two-beam conditions [19]. For example the $\mathrm{Y}$ disconnection is out of contrast in figure $8(\mathrm{a})$ and the $\mathrm{X}$ disconnection has a contrast characteristic of $\vec{g} \cdot \vec{b}<0$. In fig. 8(b), the two disconnections display opposite contrast under a common $\vec{g}$ diffraction condition. The Burgers vectors make an angle of $56^{\circ}$ with the dislocation line.

Finally, the disconnection Burgers vectors are the following, expressed in the $\lambda$ coordinate frame in units of the lattice parameter $a$ (Miller-Bravais system) :

$$
\vec{b}_{-3 /-4}=\frac{1}{3\left(\Lambda^{2}+2\right)}\left[\Lambda^{2}+2,4 \Lambda^{2}-16,-5 \Lambda^{2}+14,-3 \Lambda^{2}+18\right],
$$

where $\Lambda=(2 / 3)^{1 / 2}(\mathrm{c} / \mathrm{a})$ (see appendix),

$$
\begin{aligned}
& \vec{b}_{-3 /-4}=[0.33,0.19,-0.52,0.15], \quad\left|\vec{b}_{-3 /-4}\right|=0.423 n m \\
& \vec{b}_{-4 /-5}=\frac{1}{3\left(\Lambda^{2}+2\right)}\left[-\Lambda^{2}-2,6 \Lambda^{2}-18,5 \Lambda^{2}-20,-4 \Lambda^{2}+22\right]
\end{aligned}
$$


$\vec{b}_{-4 /-5}=[-0.33,0.56,-0.23,0.10], \quad\left|\vec{b}_{-4 /-5}\right|=0.422 \mathrm{~nm}$

Disconnections $\vec{b}_{X}$ and $\vec{b}_{Y}$ have the same component along the projection axis (but with alternate sign), eliminating the long range stress field.

These defects must accommodate the $0.8^{\circ}$ tilt deviation from the twin orientation. Among the possible defects indicated in the corresponding dichromatic pattern shown in fig. 6 the ones found in the experiment supply the necessary step height to reach the misorientation with a minimum of energy increase. Therefore, configurations with a small magnitude of $\vec{b}$ and a small step height should be favored according to both the experiment and energetic criteria. Below we discuss why some defects that obey the equation $\vec{b}=\vec{t}(\lambda)-P \cdot \vec{t}(\mu)$ are unlikely to appear. These are pictured in the dichromatic pattern on fig. 6 .

We analyze firstly the defects with small step heights $\vec{b}_{-1 /-2}$ and $\vec{b}_{-2 /-3}:$ They possess a component along the projection axis. These Burgers vectors have a glissile part along [01 $\overline{1} \overline{1}]$ that is larger than $\left|\vec{b}_{-1 /-1}\right|$, the magnitude of the rhombohedral twin shear vector $s=0.071 \mathrm{~nm}$. Such $\vec{b}_{p / q}$ dislocations can be decomposed into $\vec{b}_{p-1 / q-1}$ by emission of a $\vec{b}_{-1 /-1}$ defect and are thus unstable, as already found for $\{10 \overline{1} 2\}$ dislocations in zinc [20]. Other kinds of defects are those with no component along $\left[\begin{array}{lll}2 & \overline{1} & 1\end{array}\right]_{\lambda}$ namely pure edge defects. These defects have a length larger than $0.7 \mathrm{~nm}$ and are therefore energetically unfavorable. In the end, the observed configuration corresponds to the defects with the smallest Burgers vectors at equilibrium.

\section{3-3- Disconnection core structure}

The defect cores extend from 1 to $4 \mathrm{~nm}$. An analysis of the dislocation core has been performed on the CM300 FEG/UT instrument that has a resolution of $0.8 \AA$ after reconstruction of the complex electron exit wave function from a focal series of images [21]. Figure 9 depicts the phase of the electron exit wave function for the disconnection $\vec{b}_{-3 /-4}$. In one part of the image, the atomic columns of oxygen and aluminum are clearly distinguished (inserted magnification) at a spacing of $85 \mathrm{pm}$ [12]. In the vicinity of the disconnection, the 
image resolution is reduced (Fig. 10 (a)). The presence of a screw component is known to distort the core region of a dislocation [22]. Further, a local thickness variation may contribute to signal blur, as well.

A close inspection of the phase image at the dislocation core reveals that the dislocation is dissociated into two partials that delimit a twin boundary segment $2 \mathrm{~nm}$ wide with a different structure. The circuit made around one of the defects with translation vectors cannot be closed as the twin structure is different on each side of the partials (figure 10(a)). If we report geometrically the total circuit in the dichromatic complex, the closure failure corresponds to half of the total Burger vector $\vec{b}_{-3 /-4}$ in projection (fig. 10(b)). The simplest way to interpret the defect is to consider the partial defect as being $1 / 2 \vec{b}_{3 / 4}$. A geometric model of the corresponding "faulted" structure is in agreement with the experimental image (figure 10(c)). The twin is no longer centered on empty sites of the structure.

The disconnection energy is likely to be decreased by dissociation. Due to the large Burgers vector length $(\cong 0.42 \mathrm{~nm})$, close to those of the smallest translation vector of alumina (basal dislocation, $|\vec{b}|=0.475 \mathrm{~nm})$, several atomic planes are inserted and terminate on a same $(01 \overline{1} 2)$ plane. Dissociation here requires climb of the partials. In alumina, most lattice dislocations are dissociated by climb at high temperature [23]. This is also the case in low angle GBs in alumina [24], as well as in strontium titanate [25]. The movement of such dislocations has to be hindered by the presence of the stacking fault in the GB. Although the component of the Burgers vectors of the partial disconnections parallel to $[2 \overline{1} \overline{1} 0]$ is not exactly known at this stage, a new structure occurs between the partials: It seems centered on atoms of oxygen and aluminum rather than on symmetry centers of the structure. The width of GB disconnections in the rhombohedral twin may correlate with the strength and extent of yttrium segregation, in so far as the disconnections in the doped crystal are similar to those in the undoped bicrystal, as expected from the same disconnections characteristics at the mesoscopic level [7]. The extent of segregation perpendicular to the GB deduced from EFTEM analysis is $1.1 \mathrm{~nm}$, similar to the step height. The large width of segregation parallel to the GB could be related to the widely dissociated GB defect. Investigations of disconnections in the doped bicrystal are in progress.

\section{4-Conclusions}


The topological parameters of the disconnections in a GB close to the rhombohedral twin orientation have been identified by circuit mapping, and their magnitudes have been calculated. According to this approach, no assumptions or constraints such as a 3-dimensional coincidence lattice are required. The defects accommodate the deviation from the perfect twin orientation. Since they have a mixed dislocation character, adjacent defects exhibit twist components of opposite sign to cancel stress fields. Among the possible defects with reasonable Burgers vector and step height, the ones observed have the smallest Burgers vector.

The disconnection structure could be analyzed at the atomic level using the technique of exit wave reconstruction. The complex defect structure is characterized by a widely dissociated core whose structure is centered on atomic columns rather than on the symmetry centers of the structure found in the perfect twin. This GB structure has to be related with the wide extent of yttrium segregation in disconnection cores in favour of a lower dislocation mobility that could play a role in the reduced creep rate.

\section{Acknowledgements:}

E.A. Stepantsov and A.L. Vasiliev from the Institute of Crystallography of Moscow are gratefully acknowledged for the preparation of the bicrystals. The authors also thank U. Dahmen, R.C. Pond and J. Thibault for fruitful discussions and L. Priester for her critical reading of the manuscript. The National Center for Electron Microscopy is supported by the Director, Office of Science, Office of Basic Energy Sciences, Materials Sciences and Engineering Division of the U.S. Department of Energy under Contract No. DE-AC0205CH1123. A.Serra acknowledges the founding of MCyT project*FIS2006-12436-C02-02.

\section{Appendix :}

A bicrystal is created by joining the white $(\lambda)$ and black $(\mu)$ crystals displaying surfaces with different orientations (figure 11). The step in the boundary is related to translation vectors of each crystal, $\vec{t}(\lambda)$ and $\vec{t}(\mu)$ respectively. Thus, when a step is introduced in the GB, an 
interface dislocation arises if white and black crystal surfaces to be joined are not complementary, i.e., if $\vec{t}(\lambda)$ is not a translation vector of crystal $\mu$ and vice versa. If the interfacial structure is the same on each side of the step, the corresponding Burgers vector is given by $\vec{b}=\vec{t}(\lambda)-P \vec{t}(\mu)$ where $\mathrm{P}$ is the transformation relating the coordinate frames of the two crystals [7]. The step height is given by $h(\lambda)=\vec{n} \cdot \vec{t}(\lambda)$ and $h(\mu)=\vec{n} \cdot P \vec{t}(\mu)$, where $\vec{n}$ is the normal to the interface pointing to the $\lambda$ crystal. The notation adopted for the Burgers vector is $\vec{b}_{p / q}$, where $\mathrm{p}$ and q denote $h(\lambda)$ and $h(\mu)$ in units of the spacing $d$ of the $(01 \overline{1} 2)$ lattice planes.

The Frank coordinate system in a four dimensional space used in hexagonal and trigonal crystallography has been adopted [19]. The device exploited is a four dimensional orthogonal frame such that the Miller-Bravais symbols can be interpreted as vectors confined to a three dimensional subspace of this 4-space. The unit 4-vectors, e1, e2, e3 and e4 (e1 $=[1000]$, e2 $=[0100]$, etc..) are parallel to four mutually perpendicular axes. Miller bravais symbols for planes and directions are interpreted as 4-vectors which are confined to a particular 3-D projection of 4-space with the rule that the first three indices sum to zero. The direction [uvtw] is that of the cartesian 4-vector $[\mathrm{u}, \mathrm{v}, \mathrm{t}, \Lambda \mathrm{w}]$, and the normal to the plane (hkil) is the cartesian vector $[\mathrm{h}, \mathrm{k}, \mathrm{i}, 1 / \Lambda]$, where $\Lambda=(2 / 3)^{1 / 2}(\mathrm{c} / \mathrm{a})$, and $\Lambda^{2}=4.969$ in case of alumina. The approach combines the benefit of the Miller Bravais indexing system with the advantage of an orthogonal reference frame.

In the experimental case of figure 1 the transformation matrix represents a rotation of $180^{\circ}$ about $[01 \overline{1} \overline{1}]$ and takes the form:

$$
\left.P=\frac{1}{3 \Lambda\left(\Lambda^{2}+2\right)}\right)\left(\begin{array}{cccc}
-\left(\Lambda^{2}+2\right) & 2\left(\Lambda^{2}+2\right) & 2\left(\Lambda^{2}+2\right) & 0 \\
2\left(\Lambda^{2}+2\right) & 4-\Lambda^{2} & 2\left(\Lambda^{2}-1\right) & -6 \Lambda \\
2\left(\Lambda^{2}+2\right) & 2\left(\Lambda^{2}-1\right) & 4-\Lambda^{2} & 6 \Lambda \\
0 & -6 \Lambda & 6 \Lambda & 3\left(\Lambda^{2}-2\right)
\end{array}\right)
$$

This matrix operates on 4-D vectors as originally defined by Frank [26], which are related to vectors expressed using the Miller - Bravais system as follows: $[u, v, t, w]_{M B} \equiv[u, v, t, \Lambda w]_{4 D}$ A review of crystallographic calculations in the hexagonal and trigonal systems using these methods can be found in [27]. 


\section{REFERENCES}

[1] S. Lartigue and L. Priester, Journal of the American Ceramic Society 71430 (1988).

[2] S. Lartigue-Korinek, C. Carry and L. Priester, J. Europ. Ceram. Soc. 221525 (2002)

[3] P. Gruffell and C. Carry, "Structural Ceramics - Processing, Microstructure and Properties", Ed.

J.J. Bentzen et al, Risø National Laboratory, Roskilde, DK, 305 (1990).

[4] J. Cho, M.P. Harmer, H. Chan, J. M. Rickman, and A. M. Thompson, J. Am. Ceram. Soc., 80 1013 (1997).

[5] D. Bouchet, F. Dupau and S. Lartigue-Korinek, Microscopy, Microanalysis, Microstructures, 4561 (1993).

[6] D. Prot, M. Le Gall, B. Lesage, A.M. Huntz and C. Monty, Philos. Mag., A73, 935 (1996).

[7] D. Bouchet, S. Lartigue Korinek, R. Molins and J. Thibault, Philos. Mag., 861401 (2006).

[8] H. Grimmer, R. Bonnet, S. Lartigue, L. Priester, Philos. Mag. A, 61493 (1990).

[9] S. Lartigue-Korinek and S. Hagege, in Intergranular and Interphase Boundaries in

Materials (Trans Tech Publishing Ltd., Prague, Czech Republic, 1998), p. 281.

[10] R.C. Pond, Dislocations in Solids, ed. F.R.N. Nabarro (Elsevier Science

Publishers) 8 Chapter 38, 1-66 (1989)

[11] A.L. Vasiliev, E.A. Stepantsov, Z.G. Ivanov, E. Olsson, K. Verbist and G. Van Tendeloo, Interface Science 5223 (1997)

[12] C. Kisielowski, C.J.D. Hetherington, Y.C. Wang, R. Kilaas, M.A. O’Keefe, A. Thust, Ultramicroscopy 89243 (2001)

[13] website http://www.totalresolution.com

14] T. Geipel, K.P.D. Lageröff, P. Pirouz and A.H. Heuer, Acta Mater. 421367 (1994)

[15] T. Gemming, S. Nufer, W. Kurtz and M. Ruehle, J. Am. Ceram. Soc. 86581 (2003).

[16] A.G. Marinopoulos and C. Elsässer, Acta Mater. 484375 (2000). 
[17] H. Nishimura, K. Matsunaga, T. Saito, T. Yamamoto and Y. Ikuhara, J. Am. Ceram. Soc. 86574 (2003).

[18] R.C.Pond, N.A.MacAuley, A.Serra, W.A.T. Clark, Scripta Metall 21, 197 (1987)

[19] K. Marukawa and Y. Matsubara, Trans. JIM 20560 (1979)

[20] T. Braisaz, P. Ruterana, G. Nouet and R.C. Pond, Philos.Mag. A 75 1075-1095 (1997)

[21] W. M. J. Coene A. Thust, M. Op de Beeck and D. Van Dyck, Ultramicroscopy 64109 (1996).

[22] X. Xu, S.P. Beckman, P. Specht, E.R. Weber, D.C. Chrzan, R. P. Erni, I. Arslan, N. Browning, A. Bleloch, C. Kisielowski, Phys. Rev. Letters 95145501 (2005).

[23] K.P.D. Lagerlöf, A.H. Heuer, J.Castaing, J.P. Rivière and T.E. Mitchell, J. of Am. Ceram. Soc. 77385 (1994)

[24] A. Nakamura, K. Matsunaga, T. Yamamoto and Y. Ikuhara, Philos. Mag. 864657 (2006) [25] Z. Zhang, W. Sigle, W. Kurtz and M. Rühle, Phys.Rev.B 66214112 (2002)

[26] F.C.Frank, Acta Cryst., 18862 (1965)

[27] R.C.Pond, Sir Charles Frank: An eightieth birthday Tribute (Bristol: Adam Hilger), p. $138(1991)$ 


\section{FIGURE CAPTION}

Figure 1 : Bright field 2-beams with common $\vec{g}$ image (JEOL $2000 \mathrm{EX}$ ). The bicrystal presents two parallel arrays of disconnections called $\mathrm{X}$ and $\mathrm{Y}$ ( $\mathrm{X}$ has the strongest contrast).

Figure 2 : HRTEM (TOPCON) image of the twin recorded with the electron beam parallel to $\left[\begin{array}{lll}2 & \overline{1} & 1\end{array}\right]_{\lambda} / /[\overline{2} 110]_{\mu}$. Dislocations present large steps. The GB position is indicated by black lines.

Figure 3 : "Perfect" rhombohedral twin : (a) Comparison between experimental and simulated image (defocus $-55 \mathrm{~nm}$, thickness $15 \mathrm{~nm}$ ). The GB is centered on non-occupied Al sites (white dots, image TOPCON). (b) On the geometrical model,the octahedral sites near to the interface (schematized as 2 triangles), are slightly distorded. (Small circles correspond to aluminium columns, large circles to oxygen coumns).

Figure 4 : HRTEM image (TOPCON) recorded in the projection $[20 \overline{2} \overline{1}]_{\lambda}($ GB plane $\left.(01 \overline{1} 2)_{\lambda}\right)$. Inserted is the simulation (thickness: $5 \mathrm{~nm}$, defocus : $-39 \mathrm{~nm}$ ). The glide component parallel to the GB is visible

Figure 5 : HRTEM images of some disconnections : (a) $\vec{b}_{-3 /-4}$ (Y defect), and (b) $\vec{b}_{-4 /-5}$ (X defect). The disconnection cores display different widths and structures, which are delimited by arrows. The addditional inserted planes are indicated by the usual symbols for edge dislocations. A circuit around one Y defect is shown on (a). (Same imaging conditions as in figure 2 and 3 , the electron beam is parallel to $\left.[2 \overline{1} \overline{1} 0]_{\lambda} / /[2110]_{\mu}\right)$ 
Figure 6 : Dichromatic pattern of the rhombohedral twin. The symbols correspond to lattice sites. White symbols correspond to the cristal $\lambda$, black symbols to the crystal $\mu$. Small symbols correspond to positions at $\mathrm{z}=1 / 2$.

The circuit around the disconnection of figure 5(a) is reported in the dichromatic pattern. The Burgers vector is $\vec{b}_{-3 /-4}$. It joins $B(\mu)$ (at $4 d(01 \overline{1} 2)$ below the interface before the defect) to $B(\lambda)$ (at $3 d(01 \overline{1} 2)$ below the interface). Other possible Burgers vectors are also shown.

Figure 7: Schema illustrating the translation vectors around the step in each crystal.

The symbols correspond to lattice sites. White symbols correspond to the cristal $\lambda$, black symbols to the crystal $\mu$. Small symbols correspond to positions at $z=1 / 2$.

Figure 8 : Conventional bright field images of the grain boundary. (a) Disconnection $\mathrm{Y}$ is out of contrast. $\vec{g} \cdot \vec{b}<0$ for X disconnection. (b) The two disconnections have opposite contrast with a common g conditions. X disconnection appears white.

Figure 9 : Phase of the electron exit wave showing atomic resolution. The defect (arrowed) corresponds to $\vec{b}_{-3 /-4}$. Inserted image corresponds to an enlargement of the lower crystal. The basal plane is vertical, normal to the image. On the model, small dots correspond to oxygen columns, large dots to aluminium columns. The distance between $\mathrm{Al}$ and $\mathrm{O}$ columns is $85 \mathrm{pm}$.

Figure 10 (a) : EWR image showing another GB structure at the disconnection core (arrowed). The circuit around the partial disconnection on the right of the defect is also shown; it is not closed. 
Figure 10(b) : Circuit closed in the dichromatic complex around the partial defect of figure 10 (a). The Burgers vector $\vec{b}$ correspond to half the total Burgers vector in projection. Crystal $\lambda$ : Small circles blue: lattice sites (empty Al sites), Yellow circles : Al, Filled : $\mathrm{z}=0$ ,Open : $z=0.5$, Green circles: O. Crystal $\mu$ : Small circles orange : empty Al sites, Blue cyan circles : Al, Filled : $\mathrm{z}=0$, Open $: \mathrm{z}=0.5$, Violet circles : $\mathrm{O}$ (for colours see on-line version)

Figure 10 (c) : Core structure of the disconnection. The interface appears centered on aluminium (large circles) and oxygen columns.

Figure 11 : Schematic illustration of the formation of interfacial defects by a Volterra-like process. A defect is formed by joining crystal surfaces with incompatible steps [7]. 


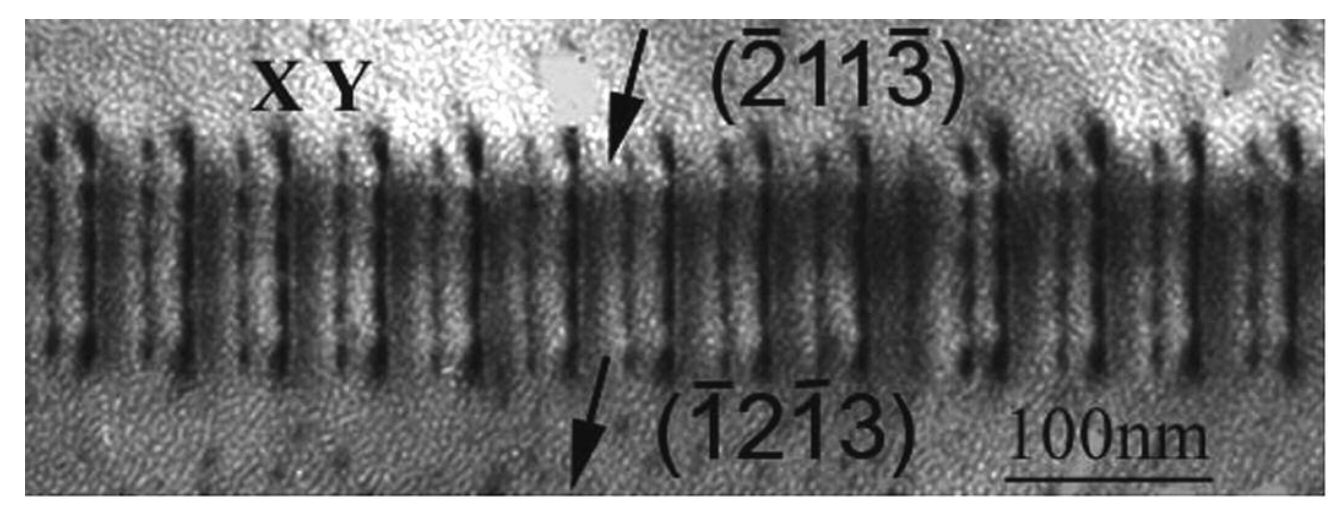

$90 \times 33 \mathrm{~mm}(300 \times 300 \mathrm{DPI})$ 


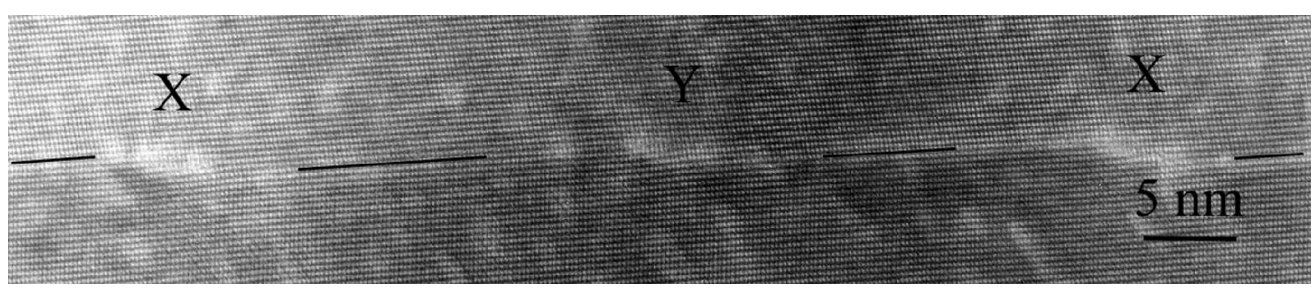

$120 \times 24 \mathrm{~mm}(360 \times 360 \mathrm{DPI})$ 


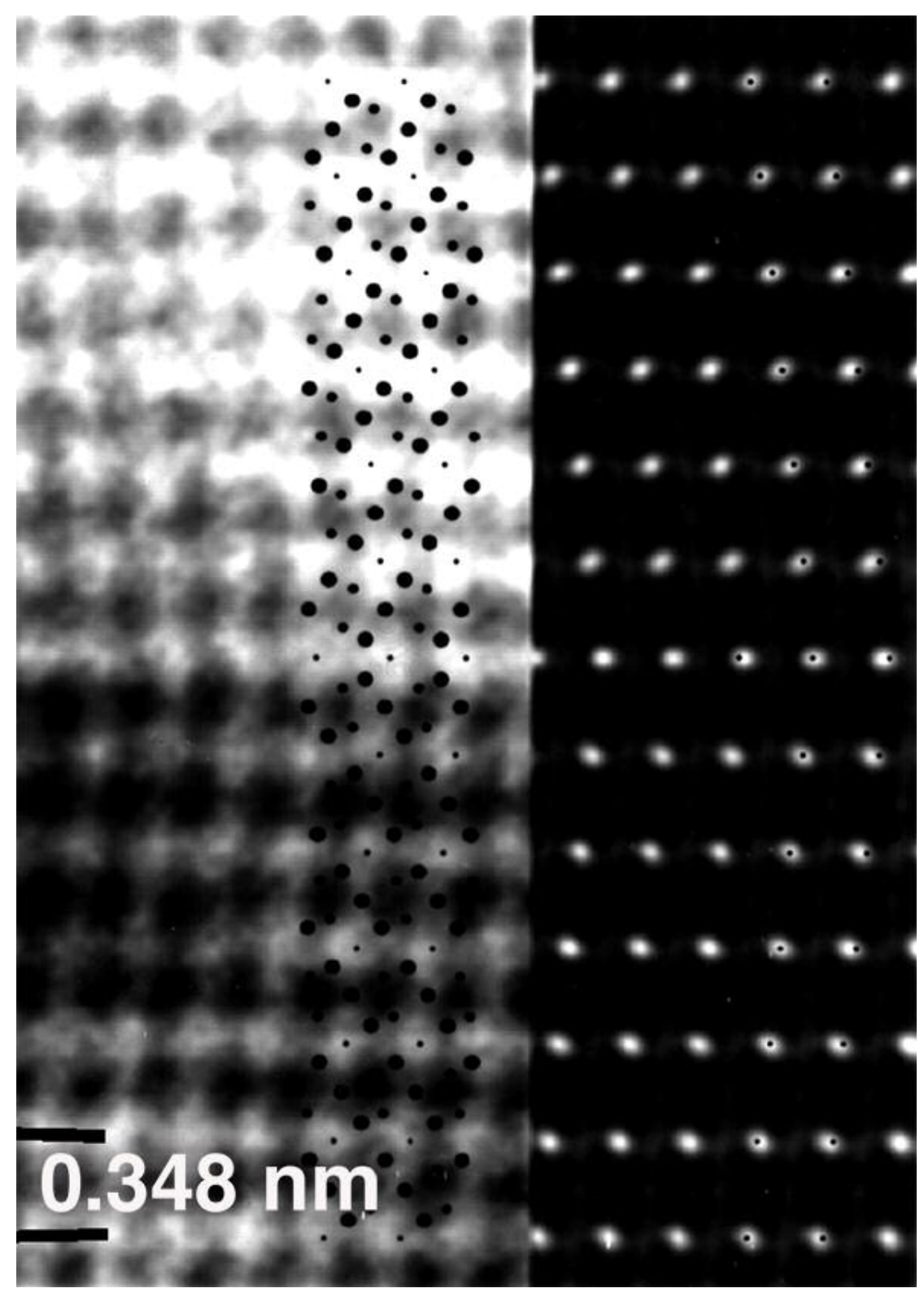

$50 \times 70 \mathrm{~mm}(300 \times 300$ DPI $)$ 


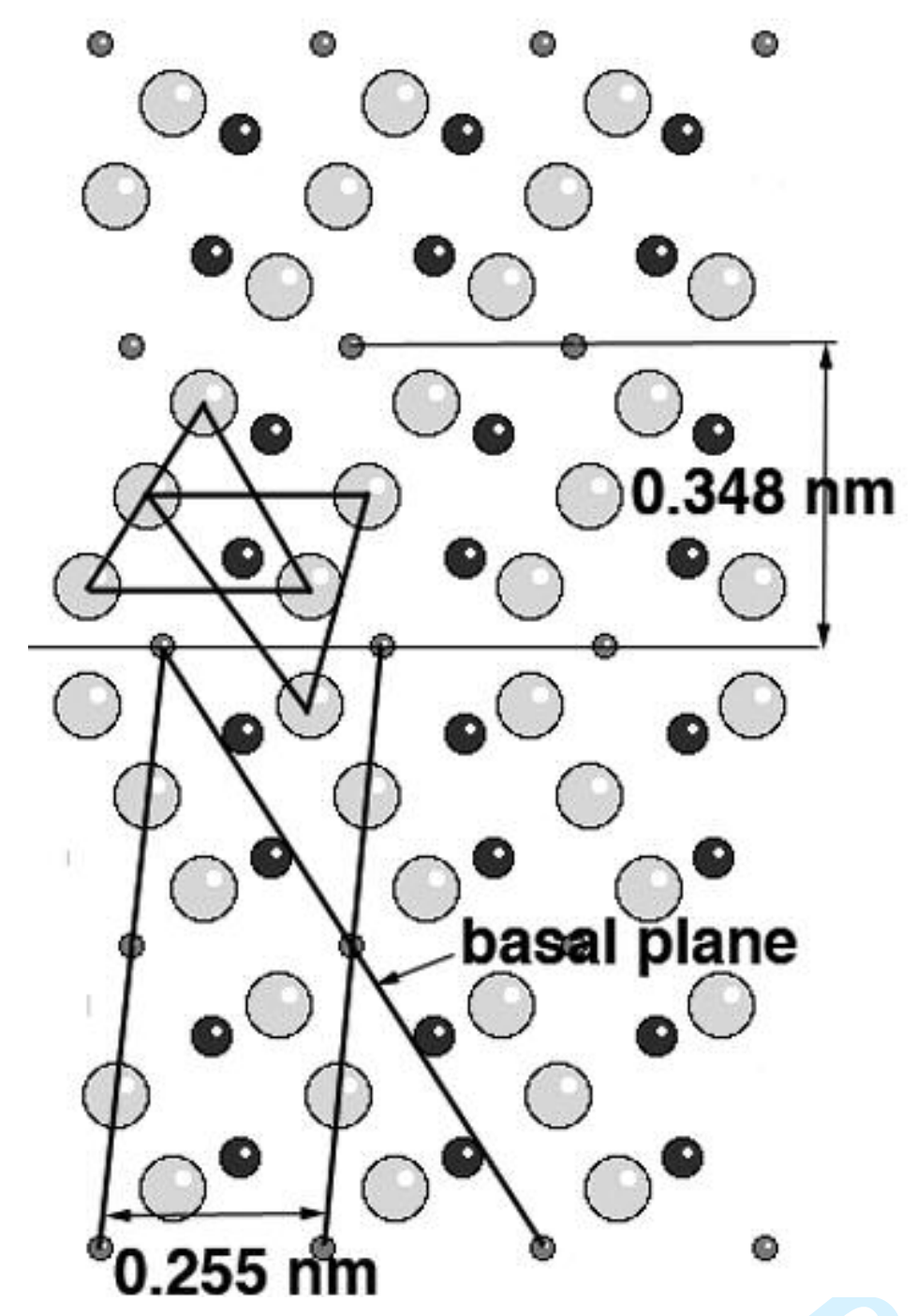




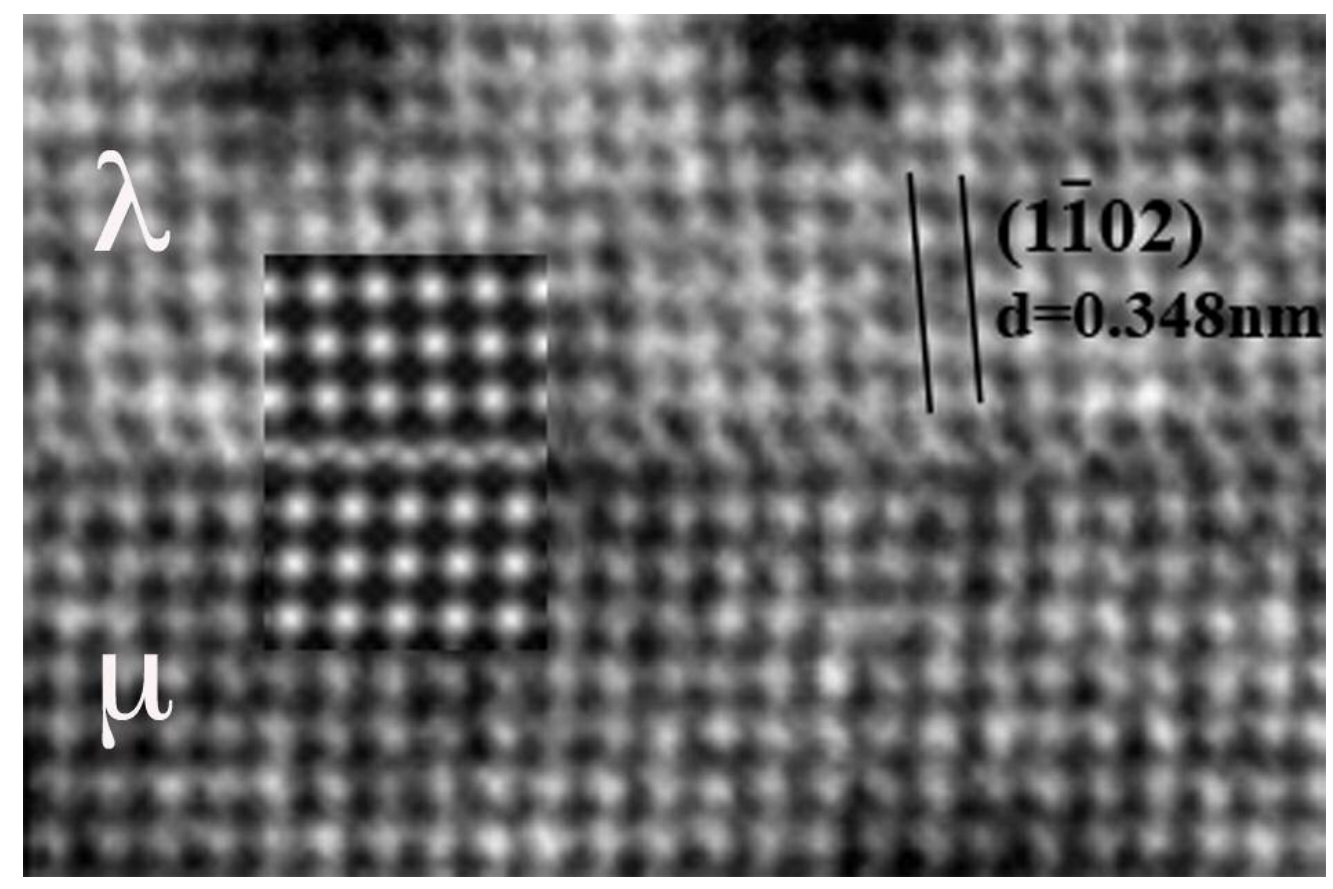

$80 \times 53 \mathrm{~mm}(300 \times 300$ DPI $)$ 


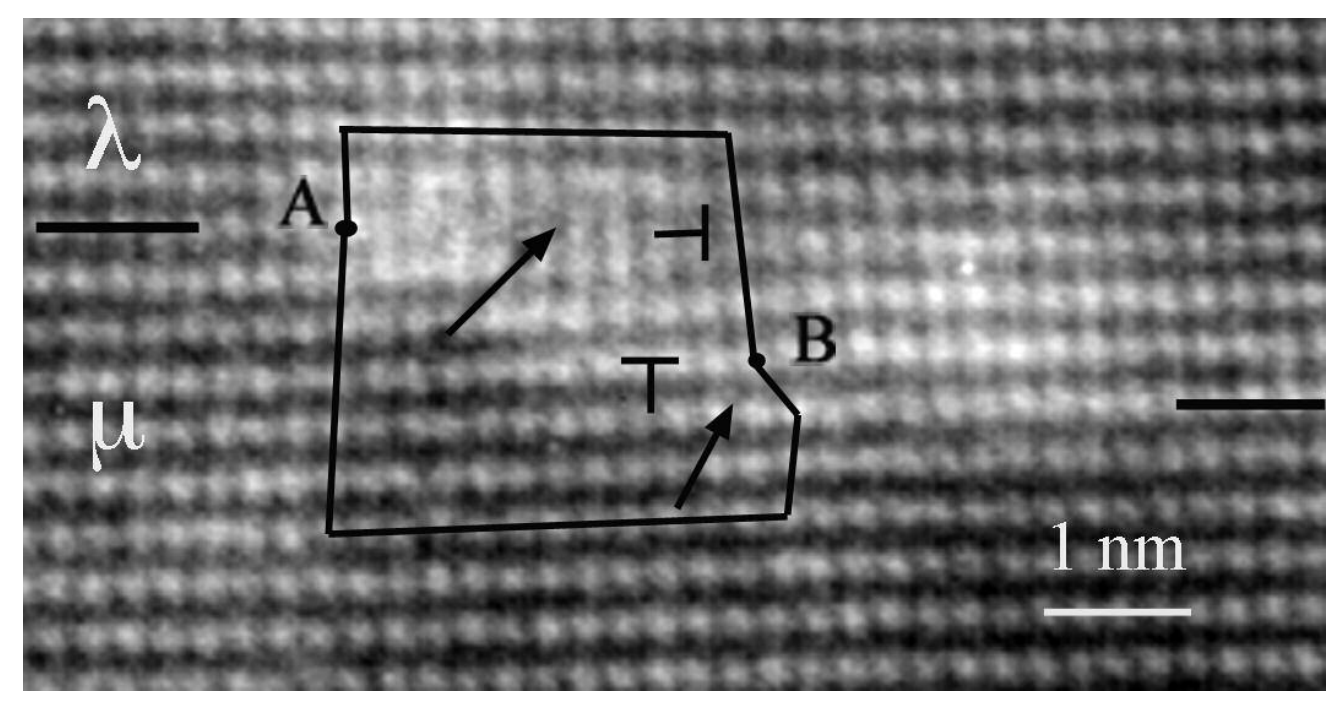

$90 \times 46 \mathrm{~mm}(300 \times 300 \mathrm{DPI})$ 


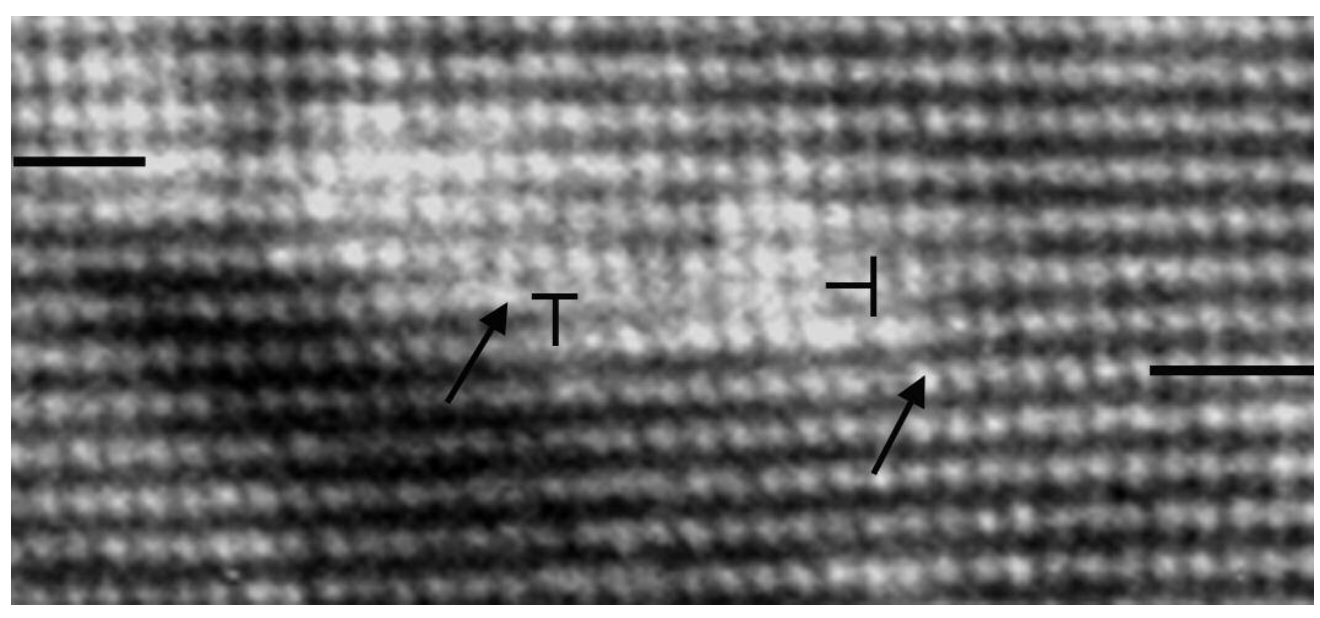

$90 \times 40 \mathrm{~mm}(300 \times 300 \mathrm{DPI})$ 


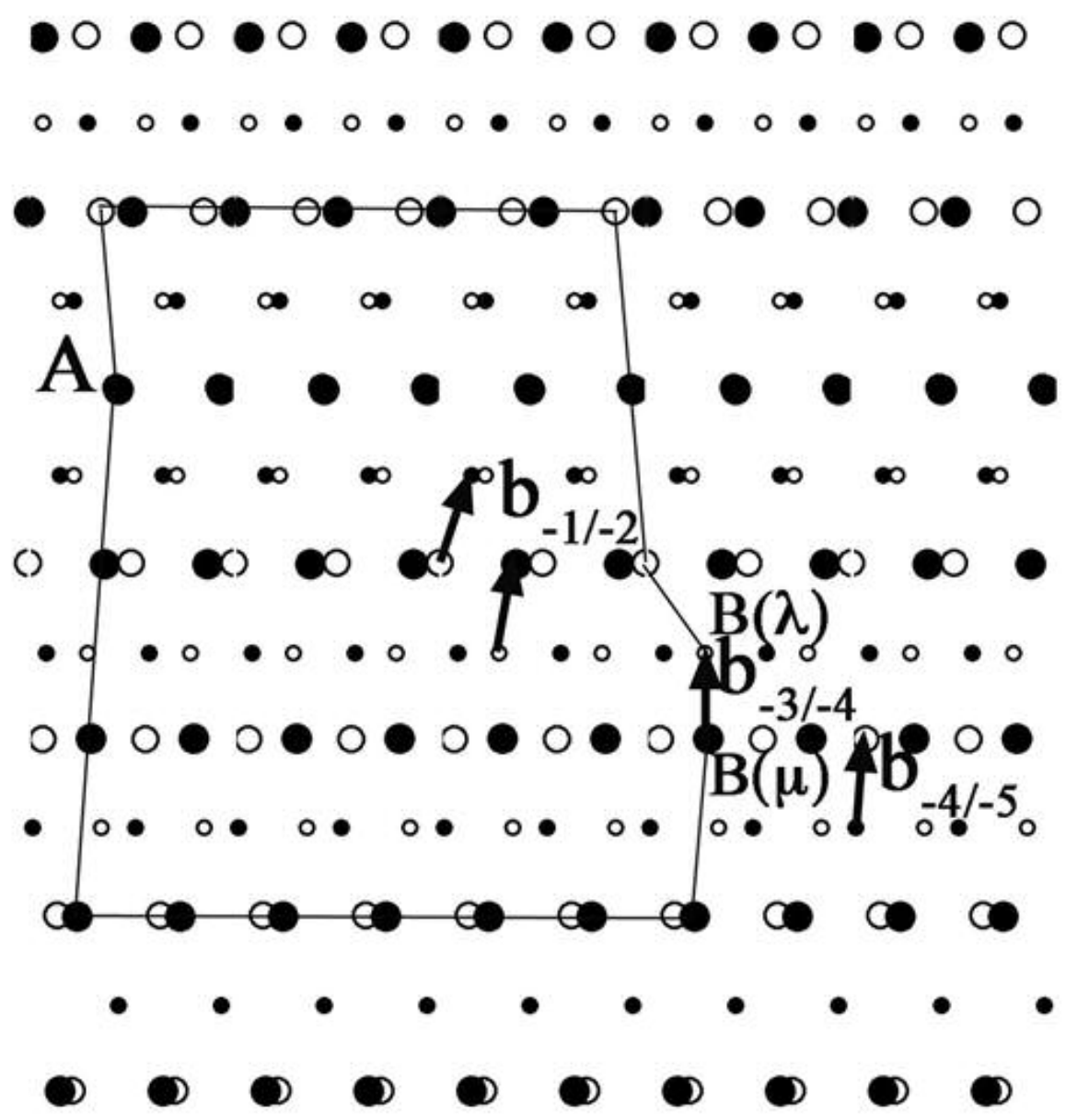

$100 \times 100 m m(144 \times 144$ DPI $)$ 


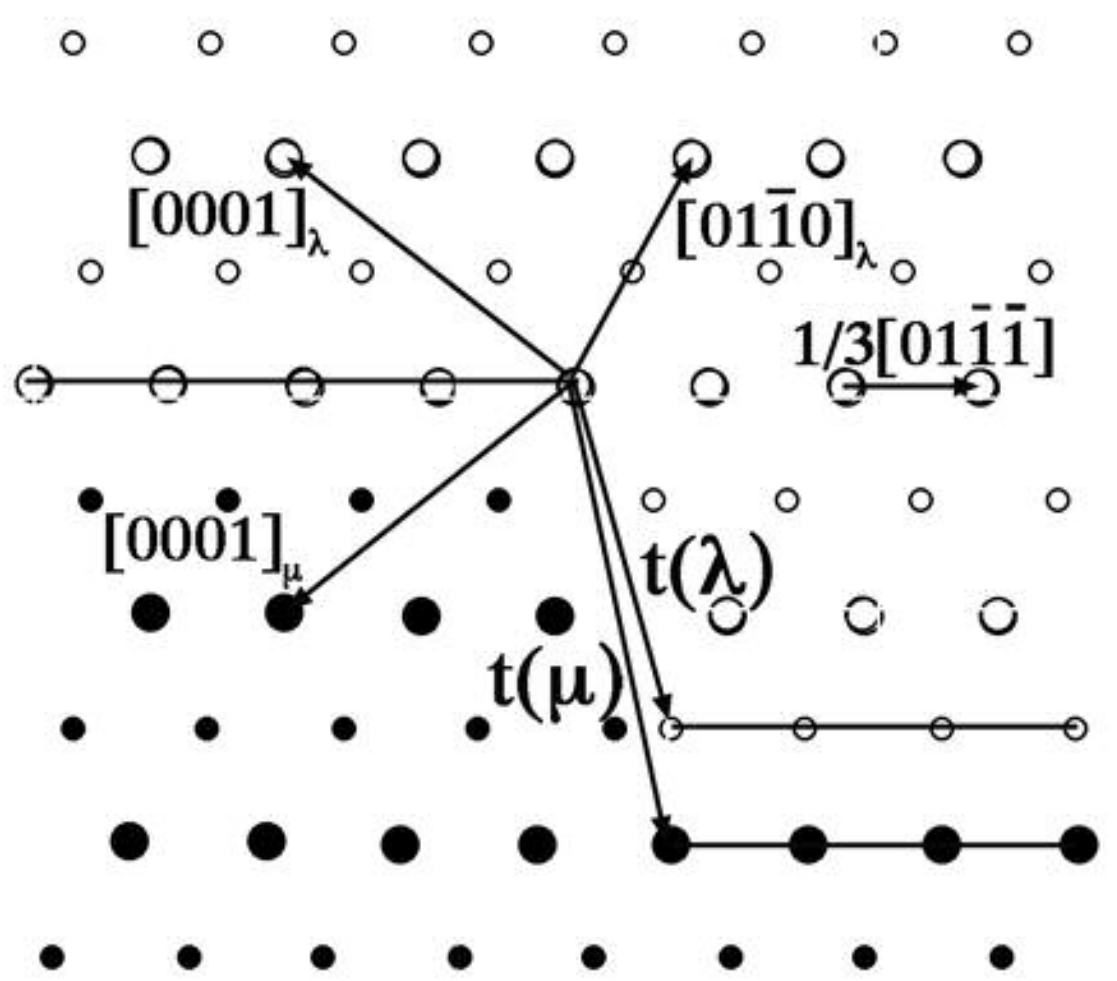

$89 \times 78 \mathrm{~mm}(144 \times 144$ DPI $)$ 


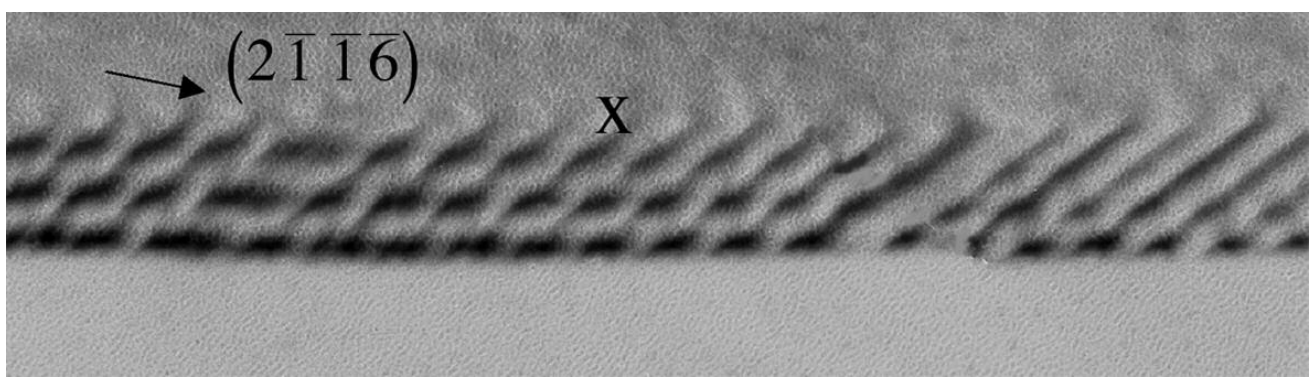

$99 \times 28 \mathrm{~mm}(300 \times 300$ DPI $)$ 


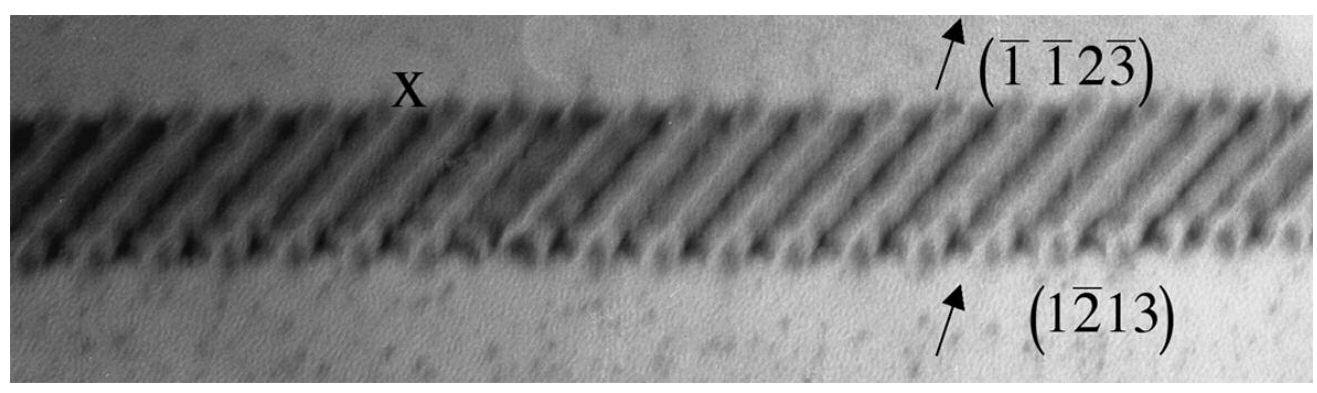

$99 \times 28 \mathrm{~mm}(300 \times 300 \mathrm{DPI})$ 


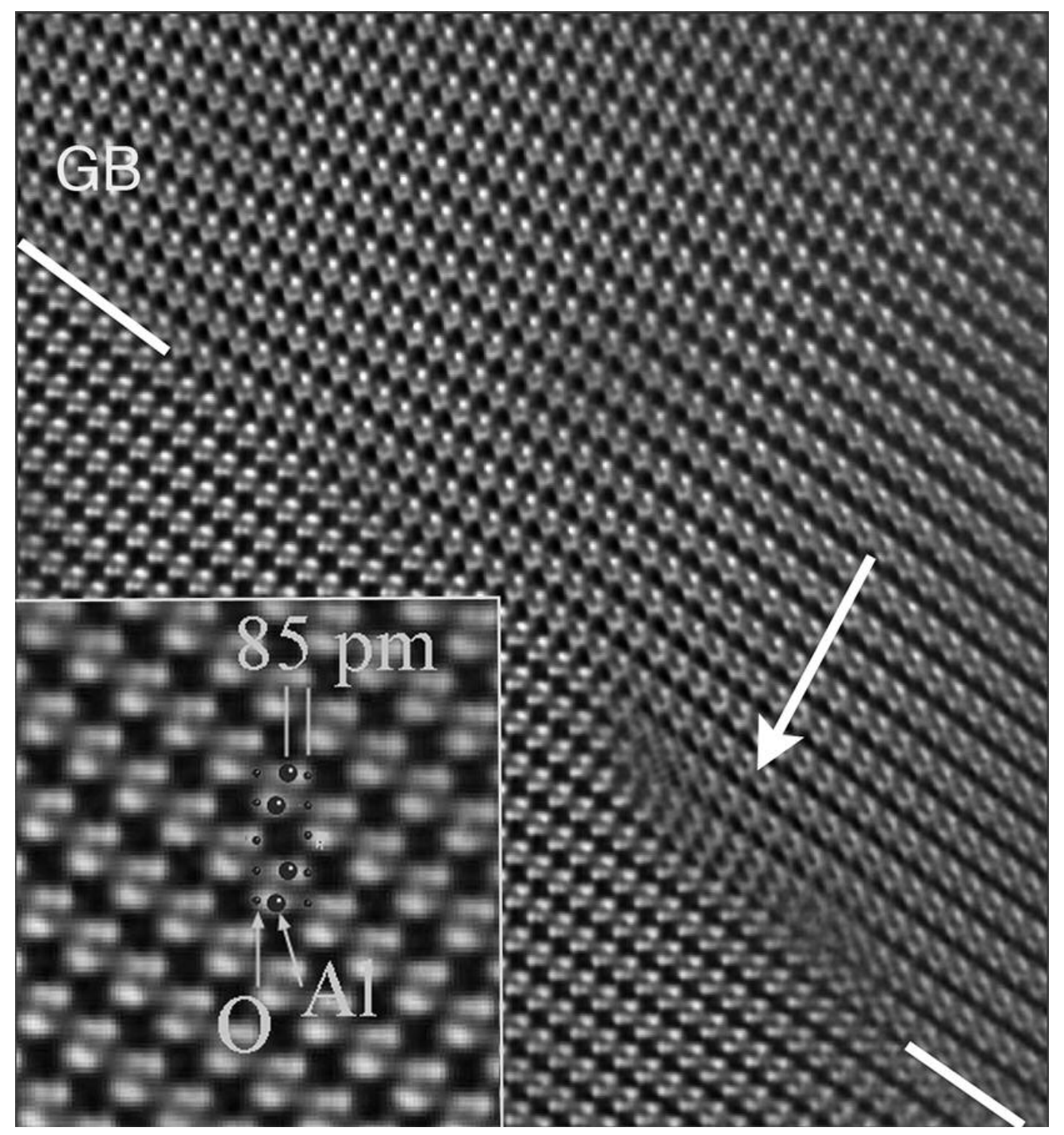

$70 \times 75 \mathrm{~mm}(300 \times 300 \mathrm{DPI})$ 


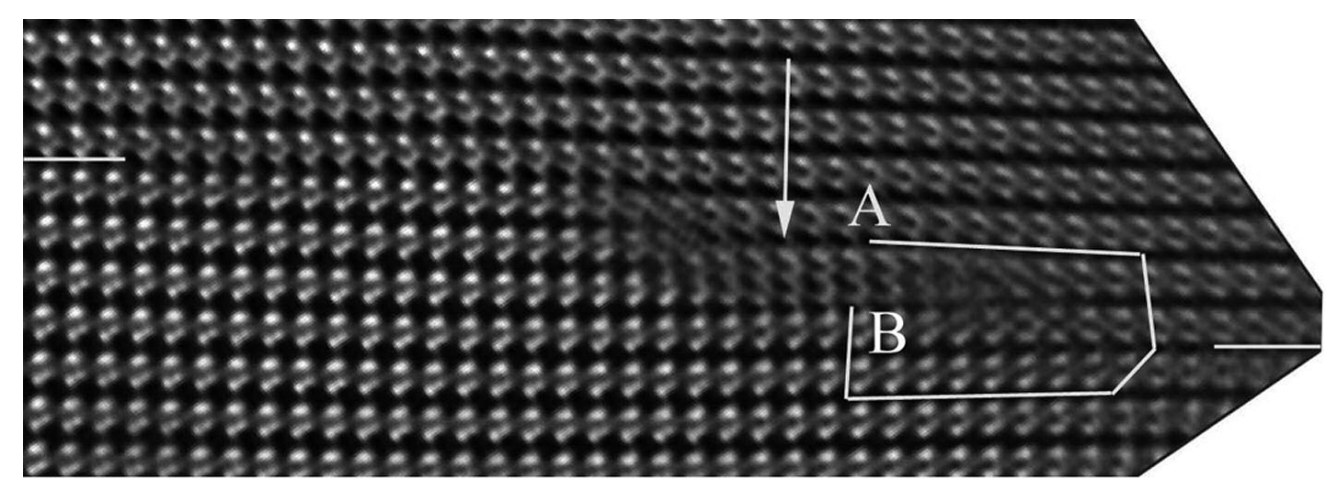

$119 \times 42 \mathrm{~mm}(300 \times 300$ DPI $)$ 


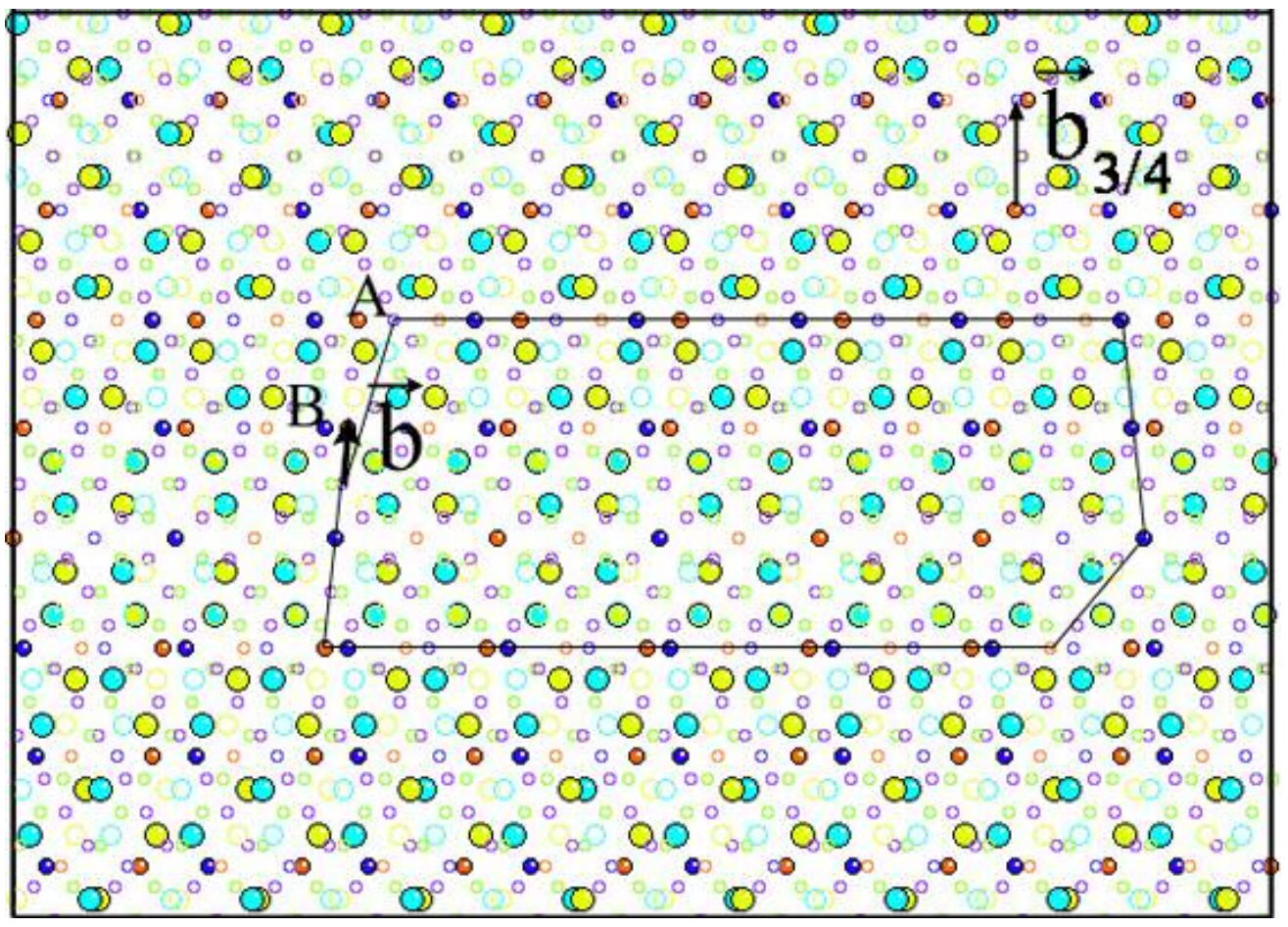

$100 \times 71 \mathrm{~mm}(144 \times 144$ DPI $)$ 


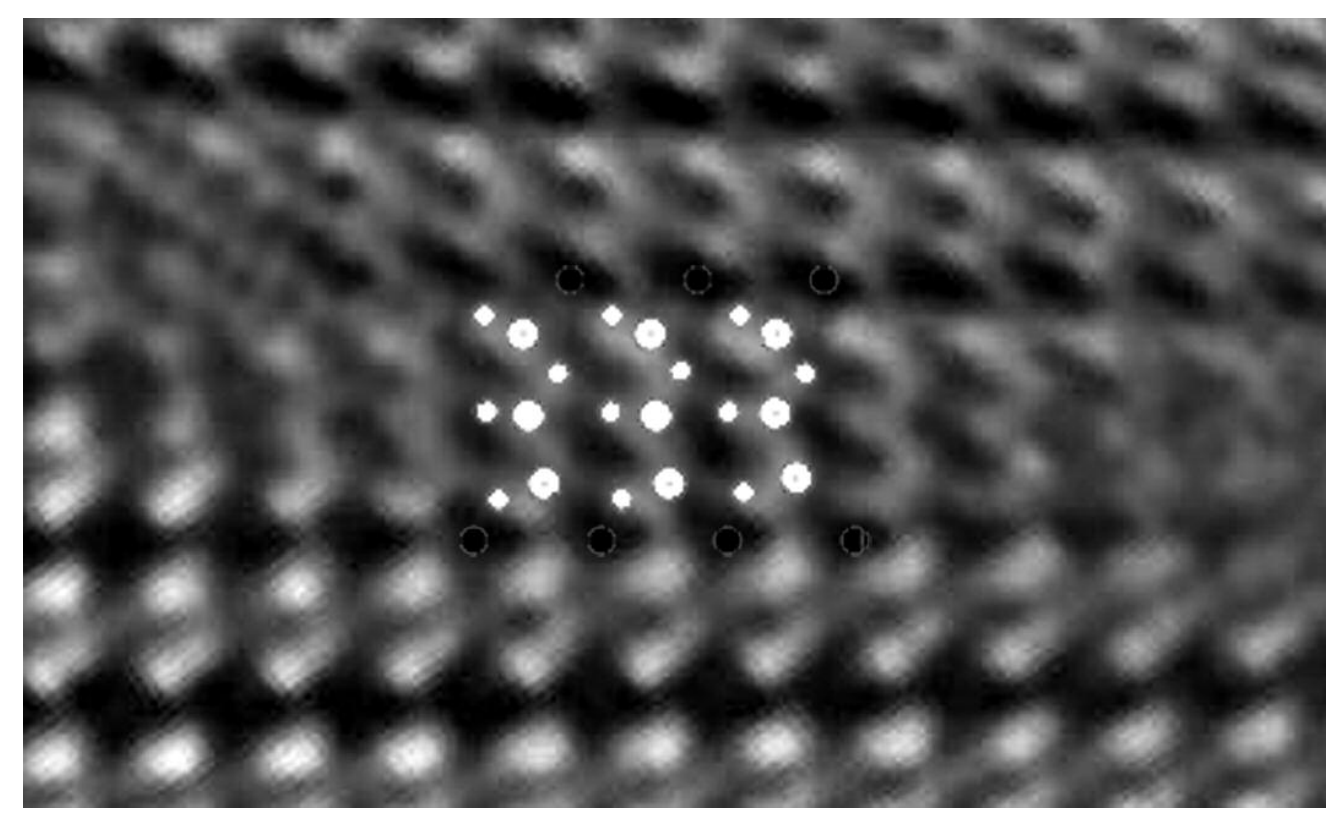

$90 \times 54 \mathrm{~mm}(300 \times 300$ DPI $)$ 

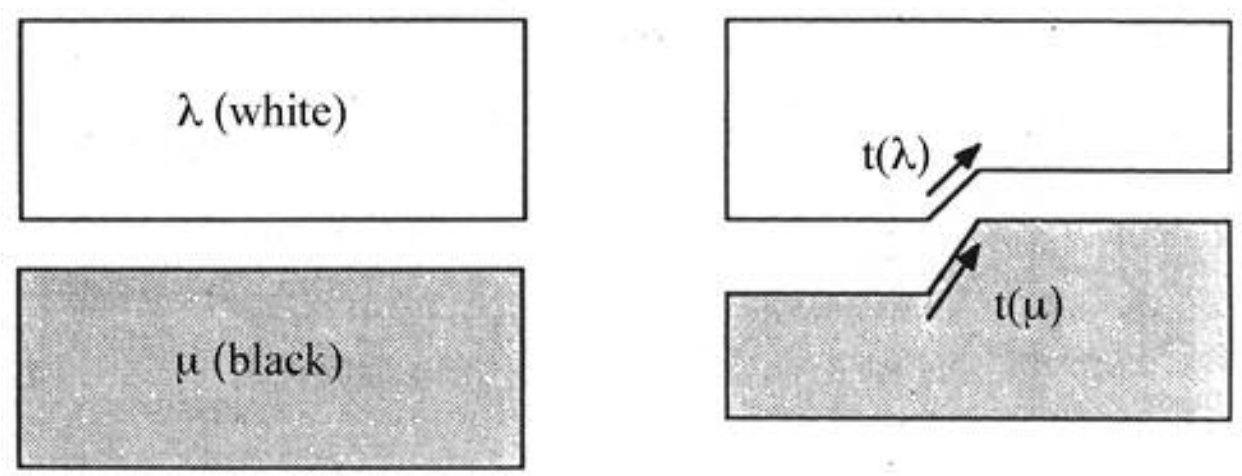

$89 \times 35 \mathrm{~mm}(144 \times 144 \mathrm{DPI})$ 